\title{
Análise da intervenção fonoaudiológica em apraxia de fala na síndrome de Down: um estudo de caso
}

\author{
Analysis of speech-language pathology \\ intervention in speech apraxia \\ in Down syndrome: a case study
}

\section{Análisis de la intervención fonoaudiológica en la apraxia del habla en el síndrome de Down: un estudio de caso}

\author{
Risayane Santos da Silva* (i) \\ Julyane Feitoza Coêlho* (D) \\ Manuela Leitão de Vasconcelos* \\ Isabelle Cahino Delgado* (iD) \\ Giorvan Ânderson dos Santos Alves* (D)
}

\section{Resumo}

Introdução: A síndrome de Down (SD), trissomia do cromossomo 21, é uma condição genética que se caracteriza por um déficit cognitivo e atraso global do desenvolvimento. Dentre as habilidades que podem apresentar fragilidades, merecem destaque as alterações envolvendo a linguagem expressiva, com comprometimentos na fala. Essas alterações podem interferir no planejamento e na programação motora, caracterizando a ocorrência da apraxia de fala na infância, um distúrbio de origem neurológica, no qual a precisão e a consistência dos movimentos subjacentes à fala são prejudicadas na ausência de déficits neuromusculares. Objetivo: Apresentar a intervenção fonoaudiológica voltada à apraxia de fala em uma criança com SD. Método: O participante foi um menino com 07 anos de idade, diagnosticado com apraxia de fala associada à SD. A intervenção foi individualizada, baseada nos princípios do aprendizado motor

* Universidade Federal da Paraíba - Paraíba, João Pessoa - Brasil.

Contribuição dos autores:

RSS: foi responsável pela coleta, análise dos dados e esboço do artigo.

JFC: contribuiu na análise dos dados e revisão da versão final para publicação.

MLV: contribuiu com a metodologia e revisão crítica.

ICD: contribuiu com a concepção do estudo e revisão crítica.

GÂSA: contribuiu com a concepção do estudo, metodologia e orientação.

E-mail para correspondência: Risayane Santos da Silva - risayane@hotmail.com Recebido: 14/06/2019

Aprovado: $10 / 09 / 2020$ 
e realizada durante 10 sessões, de 30 minutos cada. Na apresentação do caso, são abordados os dados da avaliação fonoaudiológica, os objetivos e procedimentos utilizados no planejamento terapêutico proposto. Resultados: Os dados coletados durante as sessões foram descritos e os efeitos da fonoterapia foram analisados. Os dados da reavaliação apontaram que os movimentos de praxias não verbais apresentaram melhores escores após a intervenção, sendo os resultados mais expressivos. Além disso, os resultados foram positivos quanto à estimulação para o desenvolvimento da fala, com os melhores resultados obtidos nos fonemas bilabiais $/ \mathrm{p}, \mathrm{b}$ e m/ e no fonema glotal /h/. Conclusão: A intervenção apresentou resultados satisfatórios, disponibilizando informações relevantes para uma melhor prática clínica na área.

Palavras-chave: Fonoaudiologia; Fonoterapia; Síndrome de Down; Apraxias; Transtornos da Articulação; Fala.

\section{Abstract}

Introduction: Down syndrome (DS), chromosome 21 trisomy, is a genetic condition that stands out for its cognitive deficit and global developmental delay. Among the skills that may present difficulties in the development, these skills deserve to be highlighted as changes involving expressive language, with speech impairment. These changes can interfere with motor planning and programming, characterizing the occurrence of apraxia of speech in childhood, a disorder of neurological origin, in which the precision and consistency of movements underlying speech are impaired in the absence of neuromuscular deficits. Objective: To present a speech therapy intervention aimed at apraxia of speech in a child with DS. Method: The participant was a 07-year-old boy, diagnosed with speech apraxia associated with DS. The intervention was individualized, based on the principles of motor development and performed for 10 sessions, of 30 minutes each. In the presentation of the case, it is the data of the speech therapy evaluation, the objectives and procedures used in the proposed therapeutic planning. Results: The data collected during the combinations were previous and the effects of speech therapy were approved. The reassessment data showed that the movements of non-verbal praxis had better scores after the intervention, with the results being more expressive. In addition, the positive results regarding stimulation for speech development, with the best results obtained in the bilabial phonemes $/ \mathrm{p}, \mathrm{b}$ and $\mathrm{m} /$ and in the glottal phoneme $/ \mathrm{h} /$. Conclusion: The intervention presents satisfactory results, providing high information for a better clinical practice in the area.

Key words: Speech-Language and Hearing Sciences; Speech Therapy; Down Syndrome; Apraxia; Articulation Disorders; Speech.

\section{Resumen}

Introducción: El síndrome de Down (SD), trisomía del cromosoma 21, es una condición genética que se destaca por su déficit cognitivo y retraso global del desarrollo. Entre las habilidades que pueden presentar dificultades en el desarrollo, estas habilidades merecen ser destacadas como cambios que involucran el lenguaje expresivo, con alteraciones del habla. Estos cambios pueden interferir con la planificación y programación motora, lo que caracteriza la aparición de apraxia del habla en la infancia, un trastorno neurológico en el que la precisión y la coherencia de los movimientos subyacentes al habla se ven afectadas en ausencia de déficits neuromusculares. Objetivo: presentar una intervención logopédica dirigida a la apraxia del habla en un niño con SD. Método: El participante era un niño de 07 años, diagnosticado de apraxia del habla asociada a SD. La intervención fue individualizada, en base a los principios del motor y se realizó por 10 vías, de 30 minutos cada una. En la presentación del caso, son los datos de la evaluación logopédica, los objetivos y procedimientos utilizados en la planificación terapéutica propuesta. Resultados: Los datos recolectados durante las combinaciones fueron previos y se aprobaron los efectos de la logopedia. Los datos de la reevaluación mostraron que los movimientos de praxis no verbal tuvieron mejores puntuaciones después de la intervención, siendo los resultados más expresivos. Además, los resultados positivos en cuanto a estimulación para el desarrollo del habla, con los mejores resultados obtenidos en los fonemas bilabiales / $\mathrm{p}$, bym / y en el fonema glotal / $\mathrm{h}$ /. Conclusión: La intervención presenta resultados satisfactorios, brindando alta información para una mejor práctica clínica en el área.

Palabras clave: Fonoaudiología; Logoterapia; Síndrome de Down; Apraxias; Trastornos de la Articulación; Habla. 


\section{Introdução}

A síndrome de Down (SD) é uma cromossomopatia cujo quadro clínico global é explicado por um desequilíbrio na constituição cromossômica celular $^{1}$. No Brasil, ocorre 1 caso em cada 600 nascimentos, o que significa que nascem aproximadamente 8 mil bebês com SD por ano². Desta forma, acredita-se que vivem no país 300 mil pessoas com $\mathrm{SD}$, e neste contexto a Fonoaudiologia mostra-se importante, principalmente quando se refere aos aspectos relacionados à motricidade orofacial e à linguagem oral e escrita, independente da fase da vida em que as dificuldades ocorram.

Em relação à comunicação das crianças com $\mathrm{SD}$, são mais comumente observados os comprometimentos na sintaxe expressiva, na emissão de morfemas gramaticais, na inteligibilidade e planejamento motor da fala, no vocabulário expressivo, e na memória verbal, visuo-espacial e de curto $\operatorname{prazo}^{3,4}$.

As crianças com SD apresentam grande ocorrência de ininteligibilidade da fala. Dentre as causas pode-se destacar: transtorno de fala de origem musculoesquelética; déficits envolvendo as bases motoras de respiração, fonação, articulação e ressonância, no caso das disartrias; e dificuldade na habilidade motora de planejamento da fala (programar, combinar, organizar e sequenciar os movimentos necessários para fala), no caso das apraxias $^{5,6}$.

A prevalência de tipos de distúrbios da fala e distúrbios motores da fala foi investigada em indivíduos com SD, por meio da análise de amostras de fala de 45 participantes, com idades compreendidas entre 10 e 20 anos, utilizando métodos e medidas perceptivas e acústicas do Sistema de Classificação de Distúrbios da Fala. No total, $97,8 \%$ dos participantes atenderam aos critérios para distúrbios motores da fala, incluindo disartria infantil $(37,8 \%)$, atraso motor da fala $(26,7 \%)$, disartria infantil e apraxia de fala na infância (AFI) associadas $(22,2 \%)$, e AFI isoladamente $(11,1 \%)$. Verifica-se a ocorrência de AFI tanto de forma associada como isolada, alcançando uma frequência de $33.3 \%$. Estes resultados apontam a relevância de estudos que abordem a temática, considerando desde a avaliação às implicações clínicas ${ }^{6,7}$.

A apraxia de fala é definida como um transtorno de comunicação causado por uma dificuldade na articulação, devido ao comprometimento da capacidade de programar voluntariamente a posição da musculatura dos órgãos fonoarticulatórios e na sequência dos movimentos musculares para a produção de fonemas e palavras, podendo os seus movimentos ser realizados automaticamente, mas não voluntariamente ${ }^{8}$. Especificamente, a AFI pode ocorrer como resultado de comprometimento neurológico conhecido, em associação com distúrbios neurocomportamentais complexos de origem conhecida ou desconhecida, ou como um distúrbio do som da fala neurogênico idiopático. Esse comprometimento central no planejamento e/ ou programação de parâmetros espaço-temporais das sequências de movimento resulta em erros na produção e na prosódia dos sons da fala9.

Três características segmentais e suprassegmentais são reconhecidas como de validade diagnóstica para AFI: erros inconsistentes nas consoantes e vogais nas repetidas produções de sílabas ou palavras; transições coarticulatórias prolongadas e interrompidas entre sons e sílabas; e prosódia inadequada, especialmente na realização de estresse lexical ou frasal ${ }^{9}$.

Considerando o contexto específico da SD, um estudo pioneiro investigou a abrangência com a qual a AFI estava sendo identificada por meio da percepção que os pais faziam da fala de suas crianças. Os dados mostram que $15 \%$ dos participantes relataram características clínicas da AFI em seus filhos. O exame diário das características de fala identificadas pelos pais indicou que muito mais crianças estavam apresentando sintomas clínicos da AFI, embora não tivessem esse diagnóstico. As características mais comuns incluíram diminuição da inteligibilidade, inconsistência nos erros da fala, dificuldade no sequenciamento dos sons e movimentos orais, e um padrão de linguagem receptiva superior à expressiva ${ }^{10}$. Tal resultado demonstra uma efetiva percepção dos familiares frente aos aspectos estudados. Destaca-se, entretanto, a importância de uma avaliação especializada para um diagnóstico diferencial, buscando uma melhor condução terapêutica, com impactos significativos no prognóstico clínico.

As discussões envolvendo a temática da AFI são recentes em nosso país, bem como os estudos na área ainda são incipientes. Desse modo, verifica-se uma carência de pesquisas que abordem as peculiaridades envolvidas no diagnóstico e intervenção fonoaudiológica direcionada para a AFI associada à SD, representando uma lacuna na literatura da área. 
Nesse sentido, o presente estudo traz contribuição relevante ao apresentar o delineamento de um plano terapêutico desenvolvido para uma criança com SD e AFI, promovendo uma análise dos resultados obtidos com a intervenção fonoaudiológica direcionada para as necessidades específicas do paciente.

Diante disto, o objetivo deste trabalho foi apresentar uma proposta de intervenção fonoaudiológica direcionada para o tratamento de uma criança com AFI associada à SD, descrevendo a terapia fonoaudiológica realizada, com os procedimentos clínicos utilizados e os resultados encontrados, apontando as suas principais contribuições para o caso.

\section{Apresentação do caso}

Trata-se de um estudo de caso de caráter qualitativo e descritivo. O participante do estudo foi uma criança do sexo masculino, 07 anos de idade, estudante, com diagnóstico de AFI associada à SD, atendido em uma clínica-escola de Fonoaudiologia de uma instituição pública de ensino superior. Os responsáveis pelo mesmo autorizaram a realização do estudo, por meio da assinatura do Termo de Consentimento Livre e Esclarecido, de acordo com a resolução 466/12 do Conselho Nacional de Saúde, tendo sido respeitados todos os critérios éticos. A presente pesquisa foi aprovada pelo Comitê de Ética em Pesquisa da Instituição, protocolado sob o $\mathrm{n}^{\circ}$. 1.302.829.

No período em que a avaliação fonoaudiológica foi realizada, devido à falta de instrumentos específicos para avaliação da AFI, no português brasileiro $^{11}$, optou-se por utilizar o Protocolo de Avaliação da Apraxia de Fala, que foi aplicado para avaliar as praxias não verbais e verbais.

A coleta dos dados foi realizada durante as sessões de terapia fonoaudiológica, e para a avaliação foi realizada entrevista inicial e aplicação do Protocolo de Avaliação da Apraxia de Fala ${ }^{12}$. O protocolo de avaliação é constituído de dois tipos de provas, sendo as primeiras para a avaliação da praxia não verbal com solicitação de 27 movimentos isolados e em sequência, executados após comando do avaliador. A segunda etapa de provas, para avaliação da praxia verbal, apresenta tarefas de repetição de palavras e sentenças, fala automática, fala espontânea e leitura em voz alta de palavras e sentenças. Entretanto, as respostas obtidas não foram satisfatórias devido às limitações na produção oral apresentadas pelo voluntário. Este mesmo protocolo foi reaplicado após 10 sessões terapêuticas, e todas essas etapas foram realizadas por uma única terapeuta.

Os dados foram registrados através de gravações em vídeo com duas câmeras filmadoras modelos DCR-SX22 da marca SONY. As informações coletadas durante as terapias foram descritas a fim de identificar os efeitos da intervenção na AFI associada à SD. Posteriormente, cada tarefa foi classificada de acordo com uma escala gradual de respostas: resposta correta e imediata sem hesitação (1), resposta correta, após alguns erros em tentativas anteriores (2), diminuição na amplitude, na adequação e na velocidade do movimento (3), resposta parcial (4), resposta perseverativa (5), resposta irrelevante (6), sem resposta(7) e após demonstração do avaliador $\left(^{*}\right)$.

A entrevista inicial (anamnese) foi realizada com a mãe, a qual relatou gestação tranquila e sem intercorrências. Após o nascimento da criança, ainda na sala de parto a pediatra suspeitou da SD, devido às características físicas aparentes, mas o diagnóstico de cromossomopatia foi confirmado pelo geneticista aos três meses de vida. Apresentou histórico de malformação cardíaca (sopro no coração) necessitando de acompanhamento específico na área.

Em relação à alimentação, foi amamentado exclusivamente até os sete meses de idade e de forma complementada até um ano e três meses. Segundo a genitora, o desenvolvimento psicomotor não demonstrou atraso, em relação aos aspectos esperados para sua idade cronológica, exceto no que se refere à fala. Durante o período de realização do estudo, a criança apresentava um bom estado de saúde geral, e realizava acompanhamentos fonoaudiológico, psicopedagógico e pediátrico regularmente.

No que diz respeito aos aspectos da comunicação, a genitora apresentou os resultados dos exames audiológicos de Emissões Otoacústicas (teste da orelhinha) e Potenciais Evocados Auditivos de Tronco Encefálico (PEATE) realizados, correspondendo aos padrões de normalidade. A criança realiza acompanhamento fonoaudiológico desde os três meses de idade, mas não conseguiu desenvolver uma fala compreensível, sendo a alteração anteriormente diagnosticada como atraso de linguagem e apenas recentemente havia recebido o diagnóstico de AFI. 
A mãe relatou que a suspeita da AFI veio com a não evolução do paciente mediante as terapias fonoaudiológicas realizadas, pois apesar de toda estimulação precoce e acompanhamento multidisciplinar, a fala da criança não se desenvolveu como esperado. Após o conhecimento dos pais e de discussões sobre a temática, os mesmos procuraram especialistas da Fonoaudiologia que direcionaram este diagnóstico.

Quanto aos aspectos de escolarização, a criança frequenta a escola privada de ensino regular, com metodologia inclusiva, desde os dois anos de idade, e estava cursando o $1^{\circ}$ ano do ensino fundamental. O mesmo já identificava as letras, escrevia o seu nome e realizava pequenas produções textuais, mas apresentava dificuldade nas atividades que envolviam expressão oral e diálogo com outras pessoas. Interagia bem com as outras crianças e também realizava aulas de futsal e circense.

Durante a avaliação, foi possível identificar que se tratava de uma criança calma e participativa, mostrando-se interessada e atenta a tudo que acontecia na sala de terapia. Durante todo o período de conversa com sua mãe emitiu apenas alguns balbucios, que só a genitora conseguiu entender.

$\mathrm{Na}$ avaliação oromiofuncional, identificou-se que a criança apresenta hipotonia de lábios e bochechas, hipofuncionalidade da língua, dentição mista em bom estado de conservação, respiração nasal e ausência de alterações relacionadas à mastigação e deglutição.
Com a conclusão do processo de avaliação, percebeu-se que a terapia fonoaudiológica deveria ser direcionada para melhorias na organização e planejamento dos movimentos fonoarticulatórios, através de um treino motor da fala.

Desta forma, foi montado um planejamento terapêutico baseado nas pistas tátil/proprioceptivas, visuais, auditivas e metacognitivas, visando estimular a produção de fala ${ }^{13-16}$. As dez sessões terapêuticas foram realizadas em periodicidade semanal com duração de 30 minutos. Durante o processo terapêutico, o paciente apresentou assiduidade e boa adesão ao tratamento.

\section{Resultados}

A Tabela 1 apresenta a comparação dos resultados obtidos antes e após a intervenção fonoaudiológica, com destaque para os movimentos com mudanças mais expressivas. Na avaliação inicial, a criança não conseguiu realizar nenhum comando sem a demonstração da terapeuta, como o arredondamento dos lábios, necessitando sempre de um modelo. Na reavaliação, após as dez sessões, identificou-se melhora na execução de todos os movimentos, principalmente os que a criança não conseguia realizar anteriormente mesmo com o auxílio da terapeuta, sendo estes: assobiar, passar língua nos lábios, arredondar os lábios, tocar o nariz com a ponta da língua, pigarrear, bater os dentes, articular sem som as sequencias $\mathrm{Fe} / \mathrm{Pe}$ e $\mathrm{Fe} / \mathrm{Pe} / \mathrm{Te}$.

Tabela 1. Respostas obtidas na avaliação das habilidades de praxia não verbal antes e após a terapia fonoaudiológica

\begin{tabular}{lcc}
\hline Movimentos & Resposta pré terapia & Resposta pós terapia \\
\hline Coloque a língua para fora & $2^{*}$ & 1 \\
Mostre-me como você assopra & $2^{*}$ & 1 \\
Mostre-me os dentes & $3^{*}$ & 3 \\
Arredonde os lábios & $7^{*}$ & 3 \\
Toque seu nariz com a ponta da língua & $7^{*}$ & 4 \\
Morda seu lábio inferior & $2^{*}$ & 2 \\
Assobie & $7^{*}$ & 5 \\
Passe a língua nos lábios & $7^{*}$ & 1 \\
Limpe a garganta (Pigarrei) & $7^{*}$ & $1^{*}$ \\
Ponha a língua para fora e para dentro da boca & $2^{*}$ & $1^{*}$ \\
Cerre os dentes (morda) & $7^{*}$ & $2^{*}$ \\
Mostre-me seu sorriso & $5^{*}$ & $2^{*}$ \\
Estale a língua & $5^{*}$ & $2^{*}$ \\
Mande um beijo & $4^{*}$ & $1^{*}$ \\
Bata os dentes como se estivesse com frio & $7^{*}$ & $2^{*}$ \\
\hline
\end{tabular}




\begin{tabular}{|c|c|c|}
\hline Movimentos & Resposta pré terapia & Resposta pós terapia \\
\hline Toque o queixo com a ponta da língua & $2 *$ & 1 \\
\hline Lateralize a mandíbula & $7 *$ & $4 *$ \\
\hline Mostre-me como se tosse & $3 *$ & $3 *$ \\
\hline Infle a bochecha & $5 *$ & 3* \\
\hline Lateralize a língua & $3 *$ & 3* \\
\hline Faça um bico & $4 *$ & 2* \\
\hline Alterne bico e sorriso & $5 *$ & 3* \\
\hline Eleve e abaixe a língua & $4 *$ & $3 *$ \\
\hline Ponha a língua para os lados e depois para cima & $4 *$ & $4 *$ \\
\hline $\begin{array}{l}\text { Ponha a língua para fora, feche a boca, ponha a língua } \\
\text { para dentro e abra a boca }\end{array}$ & $4 *$ & 3* \\
\hline Articule sem som a sequência $\mathrm{Fe} / \mathrm{Pe}$ & $7 *$ & 2* \\
\hline Articule sem som a sequência $\mathrm{Fe} / \mathrm{Pe} / \mathrm{Te}$ & 7* & 4* \\
\hline
\end{tabular}

Legenda: 1 = Resposta correta e imediata sem hesitação; 2 = Resposta correta, após alguns erros em tentativasanteriores; 3 = Diminuição na amplitude, adequação e velocidade; $4=$ Resposta parcial; $5=$ Resposta perseverativa; $6=$ Resposta irrelevante; $7=$ Não realiza; * = Após a demonstração do avaliador. Destaque em negrito para os resultados mais expressivos.

Além disso, foram analisados os ganhos proporcionados pela intervenção fonoaudiológica proposta para a AFI (Quadro 1).

Na sessão terapêutica inicial, utilizou-se como ponto de partida a emissão de vogais, considerando as habilidades que a criança já possuía, e a mesma correspondeu à estimulação realizada. No trabalho com os sons consonantais, inserido na segunda sessão, percebeu-se uma maior necessidade do apoio visual para realização das atividades propostas. A partir daí, verificou-se que a inserção do elemento condicionante facilitou a realização das atividades, gerando um maior engajamento, com a emissão dos sons de modo mais prolongado e articulado com o estímulo lúdico.

$\mathrm{Na}$ quarta sessão, com o uso dos exercícios isométricos, foram verificadas melhorias no treino motor com os fonemas e pela primeira vez a criança conseguiu emitir a palavra "mãe" sem distorções. Já na quinta sessão, observou-se que o uso de instrumentos musicais e imagens ajudaram a criança a focar mais na terapia, como também representa- ram uma maneira mais didática de exemplificar o ponto e modo articulatório. Na sexta sessão, após o trabalho de motricidade orofacial, a partir do treino de fala utilizando os fonemas-alvo, conseguiu produzir os fonemas isoladamente com êxito, bem como palavras monossilábicas com facilidade; já para as dissílabas demonstrou mais dificuldade, principalmente nas sílabas acompanhadas de /i/, /u/.

Na sétima e oitava sessões, foi realizado o treino com exercícios associados à fala, sendo verificadas algumas dificuldades na produção articulada dos fonemas propostos. Na nona sessão, foi estimulada a expressão verbal da criança enfatizando a emissão do /h/; o paciente conseguiu produzir o fonema-alvo associado a gestos facilitadores e realizou o reconto da história produzindo palavras distorcidas. Por fim, na décima sessão, após o trabalho de motricidade orofacial, com o apoio das pistas auditivas e visuais, o paciente conseguiu articular palavras dissílabas com êxito, inclusive falando o nome da terapeuta pela primeira vez. 
Quadro 1. Planejamento terapêutico e evolução das sessões de fonoterapia

\begin{tabular}{|c|c|c|}
\hline Sessão & Objetivos & Procedimentos \\
\hline Avaliação & $\begin{array}{l}\text { 1- Realizar entrevista inicial e avaliação } \\
\text { das habilidades de praxia verbal e não } \\
\text { verbal. }\end{array}$ & $\begin{array}{l}\text { 1- Realização de entrevista inicial e aplicação do Protocolo de Avaliação da } \\
\text { Apraxia verbal e não verbal. }\end{array}$ \\
\hline $1^{\text {a }}$ sessão & 1- Favorecer emissão de vogais. & $\begin{array}{l}\text { 1.1-Foram utilizadas pistas táteis-proprioceptivas por meio de informações de } \\
\text { posição, localização e movimento; } \\
1.2 \text {-Como também as pistas visuais por meio da imitação e figuras de bocas } \\
\text { associadas ao treino motor de fala, durante a produção das vogais /a/, /e/, /i/, } \\
\text { /o/ e / u/. }\end{array}$ \\
\hline $2^{\circ}$ sessão & $\begin{array}{l}\text { 1- Propiciar melhora no planejamento e } \\
\text { organização articulatória na produção de } \\
\text { fonemas bilabiais } / \mathrm{p} / / \mathrm{b} / \mathrm{m} /\end{array}$ & $\begin{array}{l}\text { 1.1- Foi realizada atividade de nomeação dos brinquedos, os quais iniciavam com } \\
\text { os fonemas-alvo, em tarefa lúdica. } \\
\text { 1.2- O paciente foi estimulado a articular os movimentos dos fonemas-alvos, } \\
\text { através de pistas visuais e metacognitivas (gestos articulatórios para auxiliar a } \\
\text { criança a pensar sobre o movimento). } \\
\text { 1.3-Utilizou-se o tambor para o condicionamento da criança na realização dos } \\
\text { fonemas, que deveria ser associada ao toque do instrumento. }\end{array}$ \\
\hline $3^{a}$ sessão & $\begin{array}{l}\text { 1- Propiciar melhora no planejamento e } \\
\text { organização articulatória na produção de } \\
\text { fonemas bilabiais / } \mathrm{p} / / \mathrm{b} / / \mathrm{m} / \text { associados } \\
\text { à vogais. } \\
\text { 2- Favorecer a inteligibilidade de fala. }\end{array}$ & $\begin{array}{l}\text { 1.1- O paciente foi estimulado a produzir os fonemas-alvo através de pistas } \\
\text { visuais (imagens) e metacognitivas (gestos articulatórios). } \\
\text { 1.2-Utilizou-se o tambor para o condicionamento da criança na realização dos } \\
\text { fonemas-alvo associado ao toque do instrumento. } \\
\text { 2- Foi realizado treino motor da fala através de gestos facilitadores. }\end{array}$ \\
\hline $4^{a}$ sessão & $\begin{array}{l}\text { 1- Promover aumento de tônus e } \\
\text { mobilidade da musculatura extra e } \\
\text { intra oral. } \\
\text { 2- Propiciar melhora no planejamento e } \\
\text { organização articulatória na produção de } \\
\text { fonemas bilabiais } / \mathrm{p} / / \mathrm{b} / / \mathrm{m} / \text {. } \\
\text { 3- Favorecer a inteligibilidade de fala. }\end{array}$ & $\begin{array}{l}\text { 1.1- Foi realizado exercício isométrico para lábios (protrusão de lábios sustentada) } \\
\text { e estimulação com auxílio de espátula para favorecer a elevação da língua. } \\
\text { 1.2- Uso de massagens na musculatura orofacial. } \\
\text { 2.1- O paciente foi estimulado a realizar produção verbal dos fonemas-alvo, } \\
\text { através de pistas visuais (imagens) e metacognitivas (gestos articulatórios.) } \\
\text { 2.2- Utilizou-se o tambor para o condicionamento da criança na realização dos } \\
\text { fonemas-alvo associados ao toque do instrumento. } \\
\text { 3- Foi realizado treino motor da fala através de pistas auditivas, com imitação } \\
\text { de palavras monossílabas e dissílabas com os fonemas-alvo. }\end{array}$ \\
\hline $5^{a}$ sessão & $\begin{array}{l}\text { 1- Promover aumento de tônus e } \\
\text { mobilidade da musculatura orofacial } \\
\text { 2- Propiciar melhora no planejamento } \\
\text { e organização articulatória na produção } \\
\text { de fonemas fricativos labiodentais /f//v/ } \\
\text { 3- Favorecer a inteligibilidade de fala. }\end{array}$ & $\begin{array}{l}\text { 1- Foi realizado exercício isométrico para lábios (protrusão de lábios sustentada) } \\
\text { e estimulação com auxílio de espátula para favorecer a elevação da língua. } \\
\text { 2.1- O paciente foi estimulado a realizar produção verbal dos fonemas-alvo, } \\
\text { através de pistas visuais (imagens) e metacognitivas (gestos articulatórios). } \\
\text { 2.2- Utilizou-se a flauta para o condicionamento da criança na realização do } \\
\text { fonema-alvo /f/ associado ao toque do instrumento, como também para favorecer } \\
\text { a propriocepção do ponto articulatório. } \\
\text { 3- Utilizou-se pistas auditivas (bombardeio auditivo) por meio de narrativa } \\
\text { contendo várias palavras com o som alvo, estimulando a melodia. }\end{array}$ \\
\hline $6^{\mathrm{a}} \mathrm{s}$ & $\begin{array}{l}\text { 1- Promover aumento de tônus e } \\
\text { mobilidade da musculatura orofacial. } \\
\text { 2- Propiciar melhora no planejamento e } \\
\text { organização articulatória na produção de } \\
\text { fonemas fricativos labiodentais /f//v/. } \\
\text { 3- Favorecer a inteligibilidade de fala. }\end{array}$ & $\begin{array}{l}\text { 1-Foi realizado exercício isométrico para lábios (protrusão de lábios sustentada) } \\
\text { e estimulação com auxílio de espátula para favorecer a elevação da língua. } \\
\text { 2.1- O paciente foi estimulado a realizar produção verbal, dos fonemas-alvo, } \\
\text { através de pistas visuais (imagens), táteis-proprioceptivas (input tátil } \\
\text { proprioceptivo) e metacognitivas (gestos articulatórios). } \\
\text { 2.2 Utilizou-se a flauta para o condicionamento da criança na realização dos } \\
\text { fonema-alvo /f associado ao toque do instrumento, como também para favorecer } \\
\text { a proprocepção do ponto articulatório. } \\
\text { 3.1. Utilizaram-se pistas auditivas (imitação, treino de partes). }\end{array}$ \\
\hline $7^{a}$ sessão & $\begin{array}{l}\text { 1- Proporcionar melhoria na } \\
\text { funcionalidade de língua. } \\
\text { 2- Propiciar melhora no planejamento e } \\
\text { organização articulatória na produção de } \\
\text { fonemas /t//d//l/. } \\
\text { 3- Favorecer a inteligibilidade de fala. }\end{array}$ & $\begin{array}{l}\text { 1- Foi realizado exercício isométrico para lábios (protrusão de lábios sustentada) } \\
\text { e estimulação com auxílio de espátula para favorecer a elevação da língua. } \\
\text { 2- O paciente foi estimulado a realizar produção verbal, dos fonemas alvos, } \\
\text { através de pistas visuais (imagens) e metacognitivas (gestos articulatórios.) } \\
\text { 3- Utilização de pistas táteis-proprioceptivas, visuais e auditivas }\end{array}$ \\
\hline $8^{\mathrm{a}}$ sessão & $\begin{array}{l}\text { 1- Proporcionar melhoria na } \\
\text { funcionalidade de língua. } \\
\text { 2- Propiciar melhora no planejamento e } \\
\text { organização articulatória na produção de } \\
\text { fonemas /t//d//l/. } \\
\text { 3- Favorecer a inteligibilidade de fala. }\end{array}$ & $\begin{array}{l}\text { 1- Foi realizado exercício isométrico para lábios (protrusão de lábios sustentada) } \\
\text { e estimulação com auxílio de espátula para favorecer a elevação da língua. } \\
\text { 2- O paciente foi estimulado a realizar produção verbal, dos fonemas alvos, } \\
\text { através de pistas visuais (imagens) e metacognitivas (gestos articulatórios). } \\
\text { 3- Foi realizado treino motor da fala através de pistas auditivas e visuais. }\end{array}$ \\
\hline $9^{\mathrm{a} s}$ & $\begin{array}{l}\text { 1- Promover aumento de tônus e } \\
\text { mobilidade da musculatura de lábios } \\
\text { e melhorar funcionalidade de língua. } \\
\text { 2- Propiciar melhora no planejamento } \\
\text { e organização articulatória na produção } \\
\text { do fonema /h/. } \\
\text { 3- Favorecer a inteligibilidade de fala, }\end{array}$ & $\begin{array}{l}\text { 1- Foi realizado exercício isométrico para lábios (protrusão de lábios sustentada) } \\
\text { e estimulação com auxílio de espátula para favorecer a elevação da língua. } \\
\text { 2- O paciente foi estimulado a realizar produção verbal, dos fonemas alvos, } \\
\text { através de pistas visuais (imagens) e metacognitivas (gestos articulatórios). } \\
3 \text { - Foi realizado treino motor da fala através de pistas auditivas, como também } \\
\text { utilizado o livro "A cegonha e a raposa" estimulando o reconto da história. }\end{array}$ \\
\hline $10^{\mathrm{a}}$ sessão & $\begin{array}{l}\text { Promover aumento de tônus e } \\
\text { mobilidade da musculatura de lábios } \\
\text { e melhorar funcionalidade de língua. } \\
\text { Propiciar melhora no planejamento e } \\
\text { organização articulatória na produção } \\
\text { do fonema /h/ } \\
\text { 3- Favorecer a inteligibilidade de fala. }\end{array}$ & $\begin{array}{l}\text { 1- Foi realizado exercício isométrico para lábios (protrusão de lábios sustentada) } \\
\text { e estimulação com auxílio de espátula para favorecer a elevação da língua. } \\
\text { 2- O paciente foi estimulado a realizar produção verbal dos fonemas-alvo através } \\
\text { de pistas visuais (imagens) e metacognitivas (gestos articulatórios.) } \\
\text { 3-Foi realizado treino motor da fala através de pistas táteis-proprioceptivas. }\end{array}$ \\
\hline $\operatorname{Re}$ & $\begin{array}{l}\text { 1- Reavaliar as habilidades de praxia } \\
\text { verbal e não-verbal. }\end{array}$ & 1 \\
\hline
\end{tabular}




\section{Discussão}

Considerando que o caso abordado em nosso estudo envolve uma criança com AFI associada à $\mathrm{SD}$, cabe ressaltar que a cromossomopatia traz características específicas e padrões distintos de desenvolvimento, podendo repercutir em déficits envolvendo diversos domínios cognitivos e uma co-ocorrência de alterações de fala e linguagem. Tais aspectos devem ser considerados durante o processo de avaliação e intervenção terapêutica.

Portanto, é importante entender o funcionamento cognitivo e comportamental em indivíduos com SD. Este geralmente envolve aspectos neurocognitivos e neurocomportamentais exclusivos que emergem dentro de períodos específicos de desenvolvimento, com perfis distintos que refletem as características neuroanatômicas subjacentes. $\mathrm{Na}$ primeira infância, emergem desvios leves da trajetória do desenvolvimento neurotípico. Na idade escolar, os atrasos tornam-se pronunciados. As habilidades não verbais permanecem em desenvolvimento para a idade, enquanto os déficits verbais emergem e persistem ${ }^{17}$. Conforme observado no voluntário do nosso estudo, as dificuldades na expressão oral foram mais evidenciadas no início da escolarização, acompanhando o aumento da demanda comunicativa.

Aprendizagem não verbal e memória são pontos fortes em relação às habilidades verbais. A linguagem expressiva está atrasada em relação à compreensiva. Os déficits na atenção e funções executivas estão presentes na infância e se tornam mais pronunciados com a idade ${ }^{17}$. Diante desses aspectos, pode-se verificar a relevância de uma intervenção especializada e direcionada para as necessidades do paciente.

Nesse sentido, para uma adequada condução terapêutica, é essencial uma avaliação criteriosa, tendo em vista o diagnóstico diferencial. Assim, no presente estudo, foi realizada uma análise da avaliação fonoaudiológica (Tabela 1) com o intuito de propor os objetivos e delinear os procedimentos para cada sessão terapêutica, tomando por base as características individuais do indivíduo.

$\mathrm{Na}$ avaliação das praxias verbais, a criança apresentou dificuldades, com um reduzido número de vocalizações, emissão de vogais isoladas, exibindo severos prejuízos comunicativos e déficits expressivos na inteligibilidade de fala. A literatura evidencia que, na SD, esses prejuízos são decorrentes de dois aspectos principais: as habilidades motoras orofaciais e o planejamento motor orofacial. Quando o comprometimento principal se associa à força e ao movimento dos músculos orofaciais relacionados à fala, em decorrência de alterações estruturais e funcionais, caracteriza-se o transtorno de fala de origem musculoesquelética. Já o comprometimento envolvendo a capacidade de planejar a execução dos movimentos e de combinar e sequenciar os sons é denominado de $\mathrm{AFI}^{5}$.

Clinicamente, pode-se observar nas crianças com SD dificuldades envolvendo as habilidades motoras orais, planejamento motor oral ou apresentar sintomas de ambos. Estudo realizado com 45 adolescentes com SD mostrou associação entre baixa inteligibilidade de fala e redução na precisão fonêmica e fonética, bem como inadequação de prosódia e voz. Os resultados apontaram que a disartria e a apraxia apresentaram um impacto significativo na redução da inteligibilidade de fala ${ }^{18}$.

O diagnóstico diferencial das alterações de fala presentes nos indivíduos com SD é fundamental e contribui para um melhor direcionamento e prognóstico clínico. A terapia específica para as alterações de fala de origem musculoesquelética parte do princípio multissensorial, envolvendo informação tátil, cinestésica e visual. A partir daí os passos de tratamento resumem-se em estratégias de conscientização, propriocepção, percepção auditiva e treinamento miofuncional ${ }^{13}$. Já quando nos referimos à terapia para AFI, destaca-se que é um processo longo e de lenta evolução, que tem por base recursos de compensação, atividades planejadas, monitoramento, intervenção precoce e motivação ${ }^{14}$.

A terapia fonoaudiológica para AFI deve envolver a utilização dos princípios da aprendizagem motora. Cabe reforçar a necessidade de uma avaliação detalhada para análise das condições de aquisição, retenção e transferência de habilidades motoras. A partir disso, a terapia fonoaudiológica deve ser planejada individualmente, respeitando os padrões sensoriais e as necessidades apresentadas por cada criança. De um modo geral, a fonoterapia nesses casos envolve alguns parâmetros específicos, como a escolha da quantidade de prática (pequena ou grande), distribuição da prática (massiva ou distribuída), variabilidade da prática (constante ou variável), cronograma de prática (bloqueada ou aleatória), foco de atenção (interno ou externo), complexidade do alvo (simples ou complexo) e as 
variações no feedback (quanto ao tipo, frequência e tempo) $)^{15,16}$.

Nesse sentido, foi proposto um plano de intervenção fonoaudiológica, utilizando como estratégias a repetição, escolhas dos alvos (respeitando o repertório da criança, hierarquia motora da fala e o contexto de coarticulação), pistas multissensoriais e feedback da terapeuta. Inicialmente, trabalharam-se as vogais, em seguida foi dado seguimento às sessões com fonemas estimulados de forma isolada e sequencial, com o auxílio de pistas táteis/proprioceptivas, visuais, cognitivas e auditivas.

Outro recurso considerado na intervenção foi a mioterapia, pois no paciente também foram observadas dificuldades para promover ajustes nas configurações dos órgãos fonoarticulátorios, além de apresentar limitações em alguns movimentos orofaciais, como arredondamento dos lábios e elevação da língua. Esses aspectos podem ser justificados pelos distúrbios fonoarticulátorios encontrados em indivíduos com SD, comumente associados à hipotonia muscular, que quando acentuada pode ocasionar uma menor movimentação dos órgãos fonoarticulatórios, refletindo em imprecisões articulatórias, substituições ou distorções de sons $^{19}$. Tais aspectos justificam-se, também, pelas dificuldades práxicas existentes, que prejudicam a adequada execução dos movimentos, podendo ocorrer déficits na realização de movimentos orofaciais não verbais, bem como o tateio articulatório, com a busca pelo ponto de articulação dos fonemas.

As maiores dificuldades observadas em nosso voluntário foram percebidas quando solicitadas produções sequenciadas de fonemas em comparação ao seu desempenho nas produções isoladas. Nas sessões que elencaram como alvos os fonemas que exigiam movimentos sequenciados e de elevação de língua, o paciente obteve um pior resultado, o que pode estar associado às limitações inerentes da AFI associada à $\mathrm{SD}$, as quais se caracterizam pela dificuldade com a programação voluntária, combinação, organização e sequenciamento dos movimentos necessários para a fala ${ }^{5}$.

Para verificar a evolução clínica do paciente, foram comparados os resultados obtidos pela criança nas provas de praxia não verbal, realizadas antes e após a fonoterapia. Conforme observado na Tabela 1, o paciente apresentou melhora na realização dos movimentos. Acredita-se que esses avanços foram decorrentes da terapia fonoaudiológica proposta, que estimulou a tonicidade e funcionalidade da musculatura orofacial, associada à execução de tarefas com as praxias não-verbais, visando ativar a memória dos movimentos e consolidação dos engramas motores.

Assim, o estudo evidenciou a importância da intervenção fonoaudiológica na AFI associada à $\mathrm{SD}$, tanto no que se refere aos aspectos não verbais (Tabela 1) quanto aos aspectos verbais (Quadro 1).

$\mathrm{Na}$ AFI preconiza-se que o tratamento deve abordar o estabelecimento de um inventário vocálico completo, reduzindo as omissões vocálicas e aumentando a precisão da vogal, pois os erros vocálicos têm um impacto significativo na inteligibilidade da fala ${ }^{20}$. Levando em consideração tais aspectos e as habilidades identificadas no participante, optou-se por iniciar o planejamento terapêutico propondo atividades com as vogais.

Outro aspecto terapêutico importante é fornecer às crianças acesso à comunicação multimodal, conforme necessário para facilitar a comunicação eficaz e eficiente ${ }^{20}$. Nessa perspectiva, em várias sessões foram utilizadas estratégias facilitadoras com o uso de pistas gestuais para incentivar a aquisição dos fonemas, bem como, foi estimulado o uso de tais estratégias no cotidiano da criança.

Para o trabalho com as consoantes, as estratégias utilizadas foram fornecer feedback auditivo, visual, tátil e proprioceptivo saliente para que a capacidade da criança de processar informações relacionadas ao movimento articulatório fosse maximizada. Assim, sugeriu-se o uso de entonação exagerada e ritmo lento ao falar com a criança para que ela desenvolvesse uma maior consciência dos aspectos salientes dos sons e palavras. Foi realizado, ainda, treino com o uso de exercícios motores orais associados à produção da fala, conforme referido pela literatura da área ${ }^{20}$.

Além disso, é fundamental o trabalho em estreita colaboração com as famílias, para estabelecer oportunidades regulares de prática em casa e facilitar a transferência de habilidades motoras aprendidas no tratamento para outros ambientes ${ }^{20}$. Desse modo, foi adotada a intensa comunicação com os familiares. Ao final de cada sessão, foi reservado um tempo para orientações, indicação de atividades a serem realizadas em casa e estratégias facilitadoras a serem utilizadas cotidianamente.

É importante ressaltar que o número de sessões propostas deve ser adequado à necessidade da criança, já que a intervenção fonoaudiológica para AFI deve passar pela etapa de aquisição e 
(20)

retenção das habilidades ${ }^{15,16}$. Entretanto, também devem ser consideradas as possibilidades e particularidades da família, para estabelecer a frequência do tratamento e garantir a adesão. Tendo em vista que a SD pode repercutir em diversos domínios, deve-se considerar a necessidade de uma atuação multidisciplinar junto a esses indivíduos, o que demanda uma organização da rotina familiar para suprir as necessidades sem gerar sobrecarga ou uma estimulação excessiva da criança, exigindo adaptações e flexibilização dos profissionais.

Considerando o contexto de inserção do nosso voluntário, a frequência utilizada foi de uma sessão semanal, totalizando dez sessões. Durante esse período, foram observados avanços expressivos, conforme o exposto. Aqui foram relatados apenas os resultados inicialmente obtidos com a intervenção proposta, além disso, vale ressaltar que foi dada continuidade ao tratamento com o referido paciente para o alcance de outros objetivos terapêuticos e melhorias no seu quadro clínico.

Foi observado que, com a estimulação, a criança conseguiu obter bons resultados, executando movimentos orofaciais, além de produzir fonemas e palavras que não conseguia antes. Os melhores resultados foram obtidos nos fonemas bilabiais $/ \mathrm{p}$, b e $\mathrm{m} /$ e no fonema glotal $/ \mathrm{h} /$.

Considerando as características específicas da síndrome e as peculiaridades da intervenção na área de AFI, vale destacar os benefícios alcançados com a intervenção proposta, que mesmo em um intervalo de tempo restrito e um número limitado de sessões conseguiu alcançar resultados satisfatórios, com melhorias na expressão oral e na comunicação de um modo geral.

Espera-se que os resultados deste estudo contribuam para a prática clínica na área e abram perspectivas para outros estudos com a temática em questão, contribuindo com avanços na terapia fonoaudiológica da AFI, que se apresenta como uma das alterações de fala de intervenção mais complexa, com tratamento específico, duradouro e desafiador.

É importante destacar que a terapia proposta e os resultados alcançados no presente estudo foram obtidos em um contexto particular, considerando as especificidades do paciente. Desse modo, tais resultados trazem importantes contribuições, mas não podem ser generalizados, por se tratar de um estudo de caso. Para o alcance de conclusões mais amplas e obtenção de evidências significativas, é necessária a realização de pesquisas que envolvam amostras mais amplas e delineamentos experimentais.

\section{Conclusão}

Comparando os dados pré e pós-terapia fonoaudiológica, a intervenção proposta apresentou resultados satisfatórios, com melhoras no quadro clínico tanto nos aspectos que se referem à apraxia não verbal, quanto na estimulação de fala, evidenciando as contribuições da fonoterapia. Além disso, foram disponibilizados dados importantes para auxiliar a intervenção nestes casos, com a descrição de uma proposta de planejamento terapêutico individualizada para um caso de AFI associada à $\mathrm{SD}$, baseada em pistas multissensoriais.

\section{Referências}

1. Schwartzman JS. Síndrome de Down. São Paulo: Mackenzie: Memnon; 1999.

2. Frasão Y. Down: uma nova e surpreendente visão. Rev da Soc. Bras. Fonoaudiol. 2007; (72): 10-4

3. Andrade RV, Limongi SCO. A emergência da comunicação expressiva na criança com Síndrome de Down. Pró-Fono. 2007; 19(4): 387-92.

4. Ferreira AT, Lamônica DAC. Comparação do léxico de crianças com Síndrome de Down e com desenvolvimento típico de mesma idade mental. Rev. CEFAC. 2012; 14(5): 786-791.

5. Alves GAS, Lima ILB, Lima JAS, Delgado IC. Aspectos da fala na síndrome de Down. In: Delgado IC. (Org.). Contribuições da Fonoaudiologia na síndrome de Down. Ribeirão Preto: BookToy; 2016, c. 14, p. 191-206.

6. Wilson EM, Abbeduto L, Camarata SM, Shriberg LD. Estimates of the prevalence of speech and motor speech disorders in adolescents with Down syndrome, Clin Linguist Phon, 2019; 33(8): -789.

7. Shriberg LD, Strand EA, Jakielski KJ, Mabie HL. Estimates of the prevalence of speech and motor speech disorders in persons with complex neurodevelopmental disorders. Clin Linguist Phon. 2019; 33(8): 707-736.

8. Souza TNU, Payão LMC. Apraxia da fala adquirida e desenvolvimental: semelhanças e diferenças. Rev. da Soc. Bras. Fonoaudiol. 2008; 13(2): 193- 202.

9. American Speech-Language-Hearing Association. Childhood Apraxia of Speech. 2007.

10. Kumin L. Speech intelligibility and childhood verbal apraxia in children with Down syndrome.Downs Syndr Res Pract. 2006; 10(1); 10-22.

11. Gubiani MB, Pagliarin KC, Keske-Soares M. Instrumentos para avaliação de apraxia de fala infantil. CoDAS. 2015; 27(6): 610-615.

12. Martins FC, Ortiz KZ. Proposta de protocolo para avaliação da apraxia de fala. Fono Atual. 2004; 7(30): 53-61. 
13. Tomé MC, Oda AL. Intervenção fonoaudiológica nos distúrbios de fala: a origem fonética e a origem neurológica. In: Marchesan IQ, Justino H, Tomé MC. Tratado de especialidades em fonoaudiologia. São Paulo: Guanabara Koogan; 2014.

14. Ortiz KZ. Alterações da fala: disartrias e dispraxias. In: Ferreira LP, Befi-Lopes DM, Limongi SCO. Tratado de fonoaudiologia. São Paulo: Editora Roca; 2004. p. 304-14

15. Schmidt RA, Lee TD. Motor Control and learning: a behavioral emphasis (4th ed.). Champaign: Human Kinetics; 2005.

16. Mass E, Robin DA, Hula SNA, Freedman SE, Wuulf G, Ballard KJ, Schmidt RA. Principles of Motor Learning in Treatment of Motor Speech Disorders.Am J Speech Lang Pathol. 2008; 17(3): 277-298.

17. GriecoJ, Pulsifer M, Seligsohn K, Skotko B, Schwartz A. Down Syndrome: Cognitive and Behavioral Functioning Across the Lifespan. Am J Med Genet C Semin Med Genet. 2015; 169 (2): 135-49.

18. Wilson EM, Abbeduto L, Camarata SM, Shriberg LD. Speech and motor speech disorders and intelligibility in adolescents with Down syndrome.Clin Linguist Phon, 2019; 33(8): 790-814.

19. Barata LF, Branco A.Os Distúrbios Fonoarticulatórios na Síndrome de Down e a Intervenção Precoce. Rev. CEFAC. 2010 Jan-Fev; 12(1): 134-139.

20. FishM. Here's How to Treat Childhood Apraxia of Speech (2th ed.). San Diego: Plural Publishing; 2016. 